\title{
Coronavirus (2019-nCoV) Deactivation via Spike Glycoprotein Shielding by Old Drugs, Bioinformatic Study
}

Mohammad Reza Dayer*

Department of Biology, Faculty of Science, Shahid Chamran University of Ahvaz, Ahvaz, Iran

\section{*Corresponding author:}

Mohammad Reza Dayer, Department of Biology, Faculty of Sciences, Shahid Chamran University of Ahvaz, Ahvaz, Iran. Tel/Fax: +98-6113331045, E-mail: mrdayer@,scu.ac.ir

\section{Abstract:}

The disease of COVID-19 comprises the most serious against human health worldwide with a high rate of virulence and mortality. The disease is caused by the 2019-nCoV virus from the beta coronavirus family. The virus makes use of its surface glycoprotein named S protein or spike to enter the human cells. The virus attached to its receptor named angiotensin-converting enzyme 2 on host cells surface via its receptor-binding domain and its fusion is mediated by cleavage at S2' site that is carried out by surface protease. Vaccines or drugs interfering with $\mathrm{S}$ protein binding or cleavage sites could be considered as drugs to get rid of the infection. In the current work and though docking and molecular dynamic experiments we have checked more than 100 drugs with high enough molecular weights for their shielding potency toward S protein binding sites and processing S2' sites. Our results indicate the shielding potency of:

fidaxomicin $>$ ivermectin $>$ heparin $>$ azithromycin $>$ clarithromycin $>$ eryhthromycin $>$ niclosamide $>$ ritonavir. Considering affluent reports regarding the complex disturbance in the immune system and multi-organ 
involvement in the disease there is no single or binary drug regime for cure expectedly and instead, we claim the multi-drug regime should be the choice in this context. Accordingly, we suggest our extracted drugs as an adjuvant for clinical trials.

Keywords: COVID-19, 2019-nCoV, Heparin, Ivermectin, Spike Shielding

\section{Introduction:}

Atypical pneumonia outbreak in 2019-2020 identified first in Wuhan in China's Hubei province is caused by a novel enveloped, positive-stranded RNA virus [1-3]. The virus is a new member of betacoronavirus family, including Severe Acute Respiratory Syndrome (SARS-CoV) and Middle East Respiratory Syndrome (MERS) coronaviruses called 2019-nCoV [4-5]. The disease is now called COVID-19 and accompanied by fever, cough and in advanced cases with severe respiratory distress with not wellcharacterized rate of mortality [6-7]. The virus, like other coronaviruses family, makes use of highly glycosylated S protein (spike) to enter host cells. The spike binds to angiotensin-converting enzyme 2 (ACE2) receptors in target cells with 10-20 fold higher affinity than SARS or MERS coronaviruses, the fact that underlies the high rate of virus spread between human cells as well as between individuals that leads to pandemic threat for worldwide safety [8-10]. Conformationally, spike glycoprotein is a trimeric protein belongs to class I fusion proteins. Each monomer or protomer contains 1288 amino acids in its primary structure. There are two major subunits called S1 and S2 subunits formed by cleavage of maternal string at Arg667-X668 residues (S1/S2 site) by membrane-bound furin protease to produce in mature prefusion form of the spike. In humans, the protease is expressed in multiple tissues, especially with high concentrations in alveolar cells. Protease process is essential for virus infiltration to host cells. Unlike 2019-nCoV, the SARS virus does not carry this cleavage site and so it is not dangerous as what 2019-nCoV is [11-15]. 


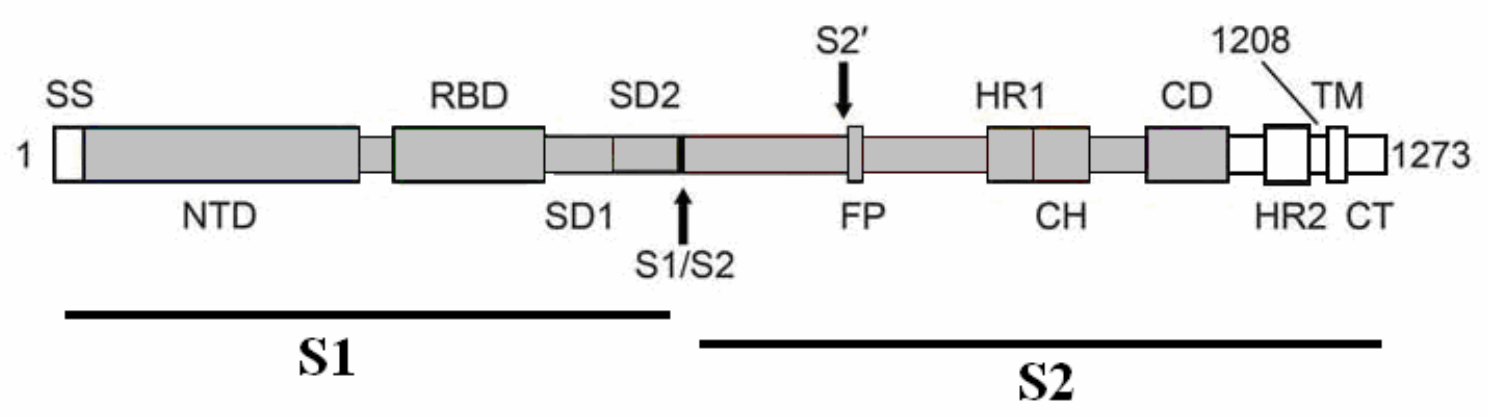

Scheme 1: graphic representation of different domains for 2019-nCoV S protein

As it is indicated in scheme 1, S1 subunit contains different functional domains beginning from Nterminus with SS (small signal sequence), NTD (N-terminal domain, residues 14-305), RBD (receptor binding domain, residues 319-541) and subdomains of 1 and 2 (SD1/SD2, residues 542-685). Considering the overall mushroom-like shape of the spike, this subunit places in the mushroom head with the RBD domain faced in such a way to interact with the cellular receptor of ACE2 [16-18]. The RBD domains of the spike trimer which are responsible for ACE2 binding adjust one of two conformations of up and down conformations. Up conformation corresponds to the receptor accessible state, while down conformation is inaccessible conformation [19-22].

The next subunit, S2 contains a signal sequence, a next cleavage site called S2' for protease. This cleavage site becomes accessible for protease action upon receptor binding to the receptor and its consequent dissociation in the prefusion state. Fusion peptide (FP, residues 788-806) domain helps the virus to fuse host cells membrane and to form the post-fusion complex. Heptad repeat 1 (HR1, residues 912-984) central helix (CH), connector domain (CD), heptad repeat 2 (HR2, residues 1163-1213), transmembrane domain (TM, residues 124-1237) and cytoplasmic tail (CT, residues 1238-1273) are the rest domains of subunit S2 [16-17].

Upon S protein binding to ACE2 receptor and cleavage at S1/S2, subunit S1 undergoes vast structural rearrangements that eventually lead to its release from prefusion complex and ultimate fusion of the virus 
with host cell [10-18]. The detailed scenario for the 2019-nCoV attack is as follows: RBD domain with up conformation preferentially binds to the ACE2 receptor. Simultaneous cleavage of S1/S2 site by protease triggers structural alterations in the S1 subunit destabilized the prefusion trimeric structure of S glycoprotein that leads to dissociation of S1 subunit and refolds S2 subunit to postfusion conformation [23-25]. Successful infection of host cells accomplished by S2' cleavage by furin protease and release of fusion peptide that is essential for postfusion state and virus entrance. The S2' site in the prefusion state is buried and inaccessible for furin but upon shedding of S1 in postfusion conformation become accessible for hydrolysis [26]. During this phenomenon heptad repeat, 1 (HR1) and heptad repeat 2 (HR2) interact with each other to form fusion core of a six-helical bundle which bringing viral and cellular membranes in close proximity for fusion. Currently, this hydrophobic core is considered as an ideal target for vaccine design or ligand interaction as effective tools to combat 2019-nCoV and COVID-19 treatment [10-18].

In the current work and through molecular dynamic/docking experiments we tried to enrollee different approved drugs to see if the can bind to RBD domain of spike protein in competition with ACE2 receptor or if they can bind to S2' region to mask it against hydrolysis by host cell protease and prevent human infections by this virus.

\section{Methods and Materials:}

Spike Coordinate: Coordinate structures of 2019-nCoV and SARS S protein with PDB ID 6VYB and 6CRZ as well as coordinate structure of ACE2 receptor with PDB ID 1O8A were retrieved from protein data bank (https://www.rcsb.org/). The structures were obtained by the X-ray diffraction and refined at the resolutions of $3.46 \AA, 3.30 \AA$ and $2.0 \AA$ respectively. The structures were energy-minimized in $12.85 \times 13.13 \times 17.12 \mathrm{~nm}, 14.68 \times 14.28 \times 17.72 \mathrm{~nm}$ and $7.21 \times 8.30 \times 7.75 \mathrm{~nm}$ separate rectangular boxes. The simulated boxes were filled with SPCE water with shells of 1.0-nm thickness. Energy minimization algorithm of Steepest descent was used to minimize the system energy to lower than $100 \mathrm{~kJ} / \mathrm{mol}$. Neutral 
$\mathrm{pH}$ ( given Asp, Glu, Arg and Lys ionized), temperature of $37^{\circ} \mathrm{C}$ and one atmospheric pressure were used as energy minimization conditions [27-28].

In order to study the dynamic behavior of spike proteins especially at RBD and fusion core we performed molecular dynamic simulations using double-precision MPI version of GROMACS 4.5.5 installed on UBUNTU version 16.04 with GROMOS force field for $20 \mathrm{~ns}$ at 37 degrees centigrade and 1 atmosphere [29].

Sequence Alignment: given the binding property of RBD domains for SARS and 2019-nCoV is determined by their amino acid sequences we compared the RBD sequence with the same sequence of SARS-CoV through sequence alignment on EMBOSS Stretcher (www.ebi.ac.uk), scheme 2, to pick up the underling principles for their different pathogenesity comparatively [30-31].

\begin{tabular}{|c|c|c|c|}
\hline $6 V Y B---001$ & 1 & RVQPTES IVRFPNITNLCPFGEVFNATRFASVYAWNRKR I SNCVADYSVL & 50 \\
\hline $6 \mathrm{CRZ}---001$ & 1 & 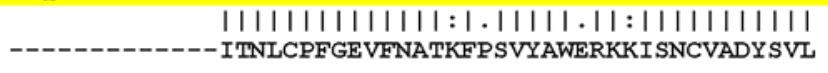 & 37 \\
\hline $6 V Y B---001$ & 51 & YNSASF-STFKCYGVSPTKINDLCFTNVYADSFVIRGDEVRQIAPGQTG- & 98 \\
\hline $6 \mathrm{CRZ}---001$ & 38 & $\begin{array}{l}|||:||||||||||-||||||||:||||||||::||:||||||||| \mid \\
\text { YNS-TFFSTFKCYGVSATKLNDLCFSNVYADSFVVKGDDVRQIAPGQTGV }\end{array}$ & 86 \\
\hline $6 V Y B---001$ & 99 & KIADYNYKLPDDFTGCVIAWNSNNLD--SKVGGNYNY-LYR-LFR--KSN & 142 \\
\hline $6 C R Z---001$ & 87 & 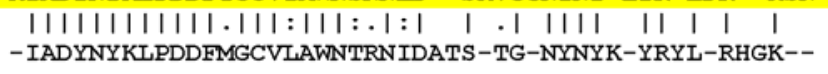 & 129 \\
\hline $6 V Y B---001$ & 143 & LKPFERDISTE I-YQA--GSTPCN-GVEGFNCYFPLQSYGFQPTNGVGYQ & 188 \\
\hline $6 \mathrm{CRZ}---001$ & 130 & 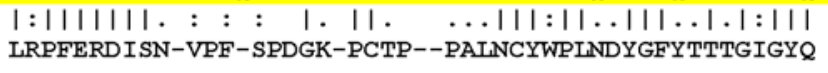 & 174 \\
\hline $6 V Y B---001$ & 189 & PYRVVVLSFELLHAPATVCGPK-KSTNLVKNKCVNF-------------- & 223 \\
\hline $6 \mathrm{CRZ}---001$ & 175 & $\begin{array}{l}\text { | |||||||||||: ||||||||| | | : | : ||: | || | } \\
\text { PYRVVVLSFELLNAPATVCGPKL-STDLIKNQCVNFNENGLTGTGVLTPS }\end{array}$ & 223 \\
\hline
\end{tabular}

Scheme 2: sequence alignment result performed of EMBOSS Stretcher (www.ebi.ac.uk) for the RBD domains (residues 319-541) from FASTA files of protein structures with PDB IDs' of 6VYB and 6CRZ.

Ligands Coordinate structures: coordinate structures for fidaxomicin, ivermectin, heparin, azithromycin, clarithromycin, niclosamide, erythromycin and ritonavir were retrieved from PubChem database (https://pubchem.ncbi.nlm.nih.gov/) as SDF format, converted to PDB format in Open Babel server (http://openbabel.org/) and optimized in ArgusLab software (http://www.arguslab.com/) [32]. 
Blind Docking experiments: to survey the potential binding potency of available drugs with high enough molecular weight and binding energy we carried out blind docking experiments in Hex 8.0.0 (http://www.loria.fr/ ritchied/hex/) using 2019-nCoV spike protein as receptor against enrolled drugs as lignds [33]. The mode of Sahpe+Electrostatic with macro sampling was used as docking parameters and the best 100 poses were analyzed accordingly.

Data Handling and Analysis: all the numerical data were exploited in Excel and SPSS software. P value under .05 was considered as the significance level.

\section{Results and Discussion:}

Studies on S proteins from SARS-CoV and 2019-nCoV origins indicated that despite large differences seen in their whole sequences and also at their domains including RBD which is determinant for receptor recognition and consequent virus infectivity, there seem to be structural similarities between these two proteins especially at their domains of NTD, RBD SD1 and SD2 from S1 subunit as well as domains of

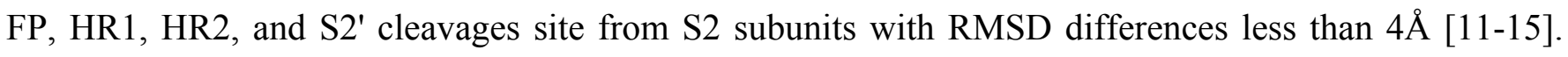
Henceforth it expected that these two proteins should behave similarly in their functions i.e. receptor recognition and host cell infection.

Given the much higher affinity of 2019-nCoV for ACE2 than SARS-CoV indicate that there should be detailed differences between these two S proteins that play a vital role in more severity of COVID-19 outbreak with high rates of virulence and mortality. Structural optimization and molecular dynamic simulations for S proteins from these two origins reveal detailed structural differences $2019-\mathrm{nCoV}$ and SARS-CoV spike proteins. Figure 1-a, represents the root mean square fluctuations (RMSF) for alpha carbons of proteins during the 20ns period of simulation for S proteins. As it is clear S protein of 2019$\mathrm{nCoV}$ expresses a lower average RMSF value of $0.52 \mathrm{~nm}$ for the whole sequence while the average 
RMSF for SARS-CoV is $0.65 \mathrm{~nm}$ and the curve of RMSF for 2019-nCoV places beneath SARS-CoV curve along the protein sequence. This means the vast alterations or mutations in the 2019-nCoV sequence lead to decreased flexibility and a more tightly folded structure for S protein of 2019-nCoV. This fact may play roles in the higher affinity of 2019-nCoV S protein for ACE2 receptor with higher infectivity. Calculations of RBD domains give $0.56 \mathrm{~nm}$ and $0.83 \mathrm{~nm}$ for $2019-\mathrm{nCoV}$ and SARS-CoV respectively. This finding may be interpreted as the more constant and more effective binding interface for RBD in 2019-nCoV.

Figure 1-b represents the superposed for these two proteins. The protein of 2019-nCoV is shown in white color while the SARS-CoV one in black. It is evident that $2019-\mathrm{nCoV}$ is surrounded by SARS-CoV protein indicating the more compacted and tightly folded structure for 2019-nCoV spike protein.
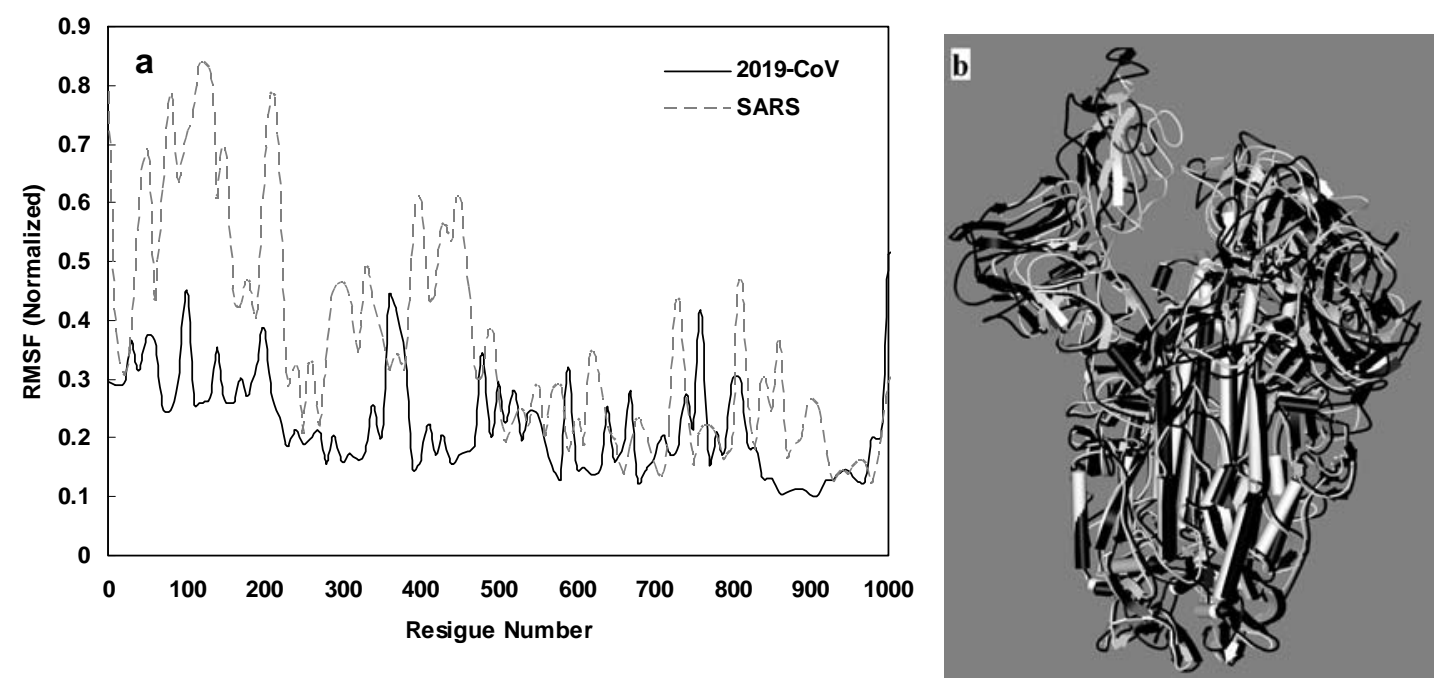

Figurt-1: a- root mean square fluctuations (RMSF) curve for 2019-nCoV and SARS-CoV spike protein extracted from trajectory file of 20ns simulation period at 37 degree centigrade, $\mathrm{pH}=7$ and 1atmosphere pressure as mean fluctuation per alpha carbon. b- Superposed structures of 2019-nCoV (white) and SARS-CoV (black) spike proteins. 
To track the detailed mechanism of S protein binding to ACE2 receptor and to determine their probable sites of interactions we preformed blind docking experiments in Hex 8.0.0 software to statistically analyzed the binding pattern and their energies of RBD domains to ACE2 receptor for the best 100 poses. Our data in table 1 indicate that there are three kinds of binding patterns being between ACE2 and RBD domains. The RBD domains may be attached to the ACE2 receptor through up or down conformations of RBD or intervening regions of RBD domains. Table 1 indicates that the $\mathrm{S}$ protein of SARS-CoV in about 53 percent of the 100 poses is attached to ACE2 binds to RBD domain using up conformation with only in 1 percent to inter RBD domains region while in the rest 46 percent poses binds with far parts of sequences contrast to RBD domains. In contrast, the S protein of the 2019-nCoV virus binds to the ACE2 receptor using down conformation of $\mathrm{RBD}$ domain in $46 \%, 10 \%$ in up conformation, and $15 \%$ of inter domains regions. Unlike previous studies, our dockings indicate that in the trimeric structure of 2019$\mathrm{nCoV}$, S protein that alike SARS-CoV protein carries one RBD in up and two in down conformation, surprisingly, this protein can binds to ACE2 receptor by RBD domains both in up and down conformation and their intervening regions with much higher binding energy $(-450.51 \mathrm{~kJ} / \mathrm{mol})$ and affinity. Our data also indicates that $\mathrm{S}$ protein of SARS-CoV mainly binds to ACE2 receptor by up conformation of RBD domain with a much less binding energy of $-379.66 \mathrm{~kJ} / \mathrm{mol}$ ( $\mathrm{p}$-value $<0.01)$. This finding may be partially helpful in understanding the higher affinity of 2019-nCov for the ACE2 receptor and its more severe virulence [19-22].

Table 1: Binding pattern of S protein RBD domains to ACE2 receptor in accordance with their binding energies extracted from docking experiments performed on HEX 8.0.0 


\begin{tabular}{|l|l|l|l|l|}
\hline & Up (\%) & Down (\%) & Inter domains region (\%) & Binding Energy(kJ/mol) \\
\hline SARS-CoV & 53 & 0 & 1 & -379.66 \\
\hline 2019-nCoV & 10 & 46 & 15 & -450.51 \\
\hline
\end{tabular}

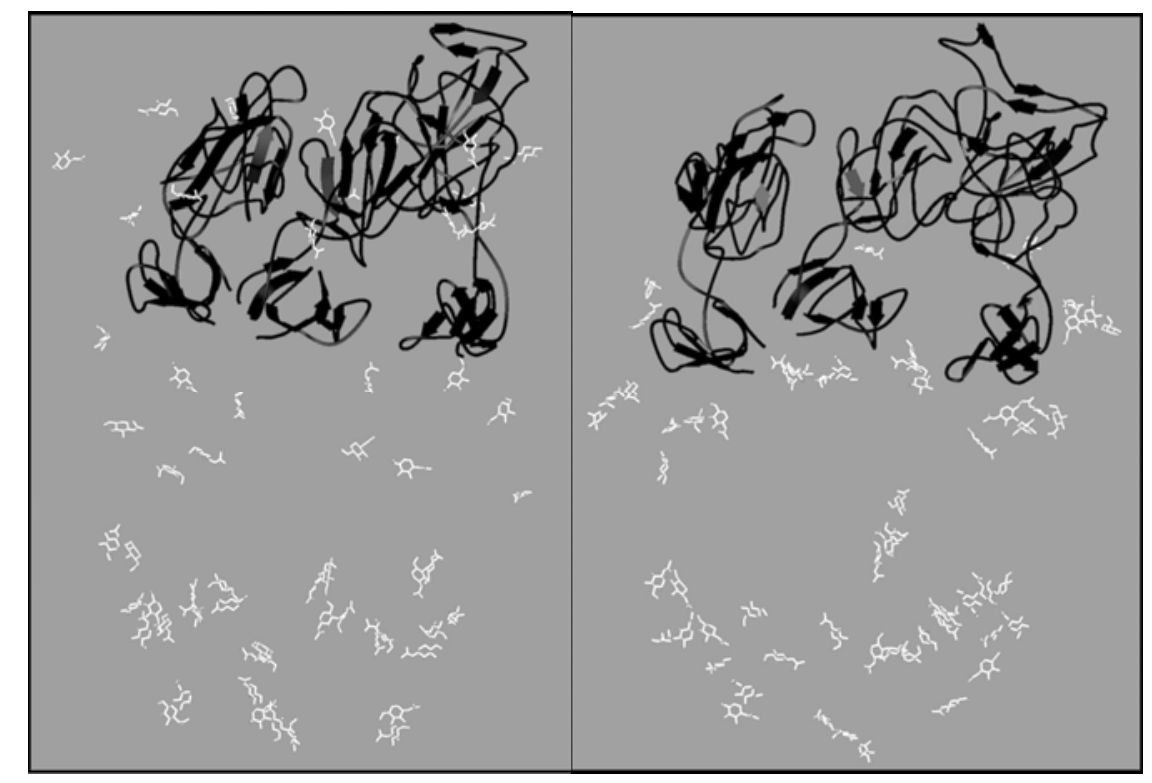

Figure 2: Schematic representation of $\mathrm{N}$-acetyl glucosamine residues distribution through trimeric $\mathrm{S}$ protein.

The next parameter that may affect the potency of interactions between S protein and ACE2 receptor is the intervening interactions posed by sugar moieties of $\mathrm{N}$-acetyl glucosamine (NAG) units that participate in hydrophobic interactions with receptor upon their interaction. Figure 2 graphically shows that contrast to SARS-CoV (right scheme), S protein of 2019-nCoV (left scheme) carries more quantities of NAG in its top side in near vicinity to RBD domains that can potentiate the interactions between RBD and ACE2 receptor upon binding [35-37]. This is the next factor that may interpret the higher affinity of 2019-nCoV S protein to host cell receptors we postulate. Isoelectric $\mathrm{pH}(\mathrm{pI})$ is the $\mathrm{pH}$ in which the protein has no net charge or the total charge of the protein is zero. Using protein sequence we have 
calculated the $\mathrm{pI}$ of proteins on www.web.expasy.org/compute pi/ as 5.82 for ACE2 receptor than at blood $\mathrm{pH}$ of about 7.4 this protein like membrane phospholipids carries a negative charge. The calculated pI for RBD domains is 7.22 and 7.89 for S proteins of SARS-CoV and 2019-nCoV respectively. These calculations reveal that at blood $\mathrm{pH}$ S protein from SARS-CoV should carry negative while 2019-nCoV positive net charge and this means that the attractive electrostatic force between ACE2 and 2019-nCoV S protein fasten their binding and describe their higher binding affinity.

Is such a sophisticated highway of mechanistic studies different ways are now suggesting to combating or deactivating 2019-nCoV infections from S protein and ACE2 receptor interaction points of view. Among these ways shielding the $\mathrm{S}$ protein by small ligands, designing a vaccine against $\mathrm{S}$ protein, and/or injection of soluble forms of recombinant ACE2 to prevent or misled virion to attacks human cells receptors are more advised recently [10-18, 33-35]. Our docking results reveal that there is a significant correlation between drug molecular weights and their binding energies. Accordingly, we then have enrolled more than 100 candidates from approved drugs with high enough high molecular weights for docking and to chose drugs with considerable binding energy to S protein contrast to ACE2 receptor to suggest them as candidates to combat 2019-nCoV infections after clinical approval. 


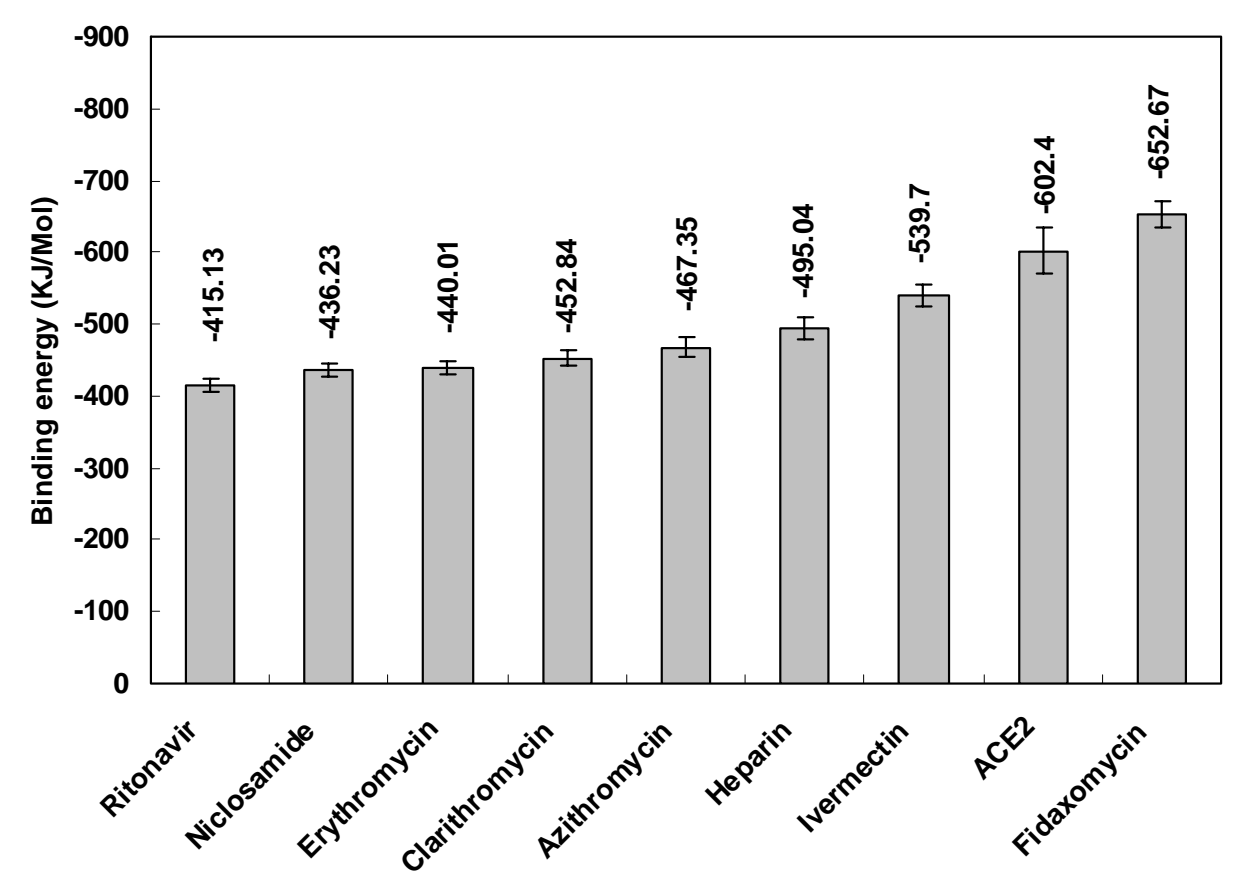

Figure 3: binding energies of selected nine drugs in accordance with to ACE2 to S protein extracted as Mean \pm SD from blond docking experiments performed on Hex 8.0.0

Finally and among the enrolled drugs, we have selected nine drugs with comparable potencies including fidaxomicin, ivermectin, heparin, azithromycin, clarithromycin, niclosamide, erythromycin, and ritonavir. Fidaxomicin represents the highest binding energy of $-652.67 \pm 19.19 \mathrm{~kJ} / \mathrm{mol}$ and the highest affinity for S protein. Unfortunately, we find that fidaxomicin does not bind via RBD domains to S protein, and instead, it binds merely to S2' site region and can prevent virus engagement to host cells in the late stage of activation. Ivermectin, is a medication used to treat parasite infestations, reveals binding energy of $-539.7 \pm 16.19 \mathrm{~kJ} / \mathrm{mol}$ that is significantly lower than that's of ACE2 receptor binding energy of $-602.4 \pm 31.28 \mathrm{~kJ} / \mathrm{mol}$ ) in more than $45 \%$ of docking poses to RBD domains and in about $20 \%$ to $\mathrm{S}^{\prime}$ cleavage site and accordingly inhibits virus attachment to RBD domain in the first step and also prevents virus activation in late phase [38-39]. The next selected drug is heparin (MW=1134.9gr/Mol) which 
shows the binding energy of $-495.04 \pm 14.94 \mathrm{~kJ} / \mathrm{mol}$. Our docking experiments indicate that heparin can extensively mask RBD and S2' regions against their accessibility for ACE2 binding and protease cleavage. Heparin is a medication used as an anticoagulant to treat heart attacks and unstable angina as intravenous or subcutaneous injections [40-41]. Bleeding, painful injected sites, decreased counts of platelets, and thrombocytopenia is the major drawbacks of heparin prescription. Nevertheless, there are reports showing that heparin beyond its anti-coagulation nature, shows the useful anti-inflammatory effect, decreasing immune cell recruitment, neutrophil activation, and degranulation [42-43]. Given the negative charge of heparin and previously mentioned positive charge of S protein, we hypothesize that the electrostatic binding forces between heparin and $\mathrm{S}$ protein are much higher than that undertaken in docking experiments performed by Hex software. Moreover, it is very important to mention that the heparin used in our experiments medicinally considered as ultra-low molecular weight heparin with 5 sugar residues. This kind of heparin is used primarily in acute coronary syndrome, pulmonary embolism, and deep venous thrombosis. In practice, low molecular weight heparin with higher molecular weight and more sugar residues range from 4 to 22 than what we used is the most favorable and more prescribed form of heparin in the clinic. This fact clearly indicates that such type of heparin expectedly will exert more shielding effects on S protein than what we claimed and can prevent virus entrance to human cells [44]. The macrolides antibiotics of azithromycin, clarithromycin, and erythromycin used in our experiments with binding energies of $-468.35 \pm 13.88,-452.84 \pm 10.8$ and $-440.01 \pm 9.04 \mathrm{~kJ} / \mathrm{mol}$ respectively comprises good anti-viral candidates. Taking into account that macrolide with confirmed immunomodulatory effects makes them valuable candidates for further studies in COVID-19 therapy [45-48]. Additionally, deliberate reviews on docking pose for macrolides indicate that they are capable to shield RBD domains as well as S2' cleavage sites. Niclosamide is an anthelmintics drug used to treat worm infections with broad antiviral properties is the penultimate candidate in this series [49]. Our 
docking experiment shows that niclosamide has a binding energy of $-436.23 \pm 9.78 \mathrm{~kJ} / \mathrm{mol}$ for S protein but like fidaxomicin can only bind to S2' region and can only prevent 2019-nCoV activation in late phase and host cells invasion. Among anti-HIV drugs only ritonavir with a molecular weight of $720.94 \mathrm{gr} / \mathrm{Mol}$ can bind to $\mathrm{S}$ protein with comparable energy of $-415 \pm 10.09 \mathrm{~kJ} / \mathrm{mol}$ and can act as shielding drugs in addition to its anti-protease activity. It is very important to mention that even though the binding energies of our shielding candidates except fidaxomicin are significantly lower than the binding energy for ACE2 receptor in 1:1 competition ratio but we should remember that in pharmacological dosage the ratio of drug/ACE2 receptor is far from unity and so we can expect that the total binding energies of shielding candidates are much higher than ACE2 receptor and hence they will comprise logic shield toward viral infections.

\section{Conclusion:}

To this end, the disease of COVID-19 with a high rate of virulence and fast spread in the human body with multi-organ involvement and high rate of mortality comprises the greatest problem since the Second World War with more than 3 millions infected cases and more than 218,000 deaths by April 2020 [5052]. Decreased lymphocytes, increased $\mathrm{C}$ reactive protein (CRP), and pro-inflammatory cytokines as well as hypercoagulability with increased d-dimer lead to lung lesions with infiltrated immune [53-56]. It seems credulous to think that in a battle against COVID-19 that invades multi organs and disturbs the immune defensive system in a short period to be achieved by one or two drugs, especially at an advanced state. Based on plentiful reports in this context and considering our current and previous work [57] we imagine that a successful treatment regime should contain multi drugs of protease inhibitors, spike shielding drugs, and immunomodulatory drugs in early steps of the disease. Ivermectin>heparin (as intravenous or nebulized) $>$ macrolides seem to be good adjuvant candidates in all anti 2019-nCov regimes to shield S protein even for prophylactic purposes. 


\section{Acknowledgements}

The author would like to express his thanks to the vice chancellor of research and technology of Shahid Chamran University of Ahvaz for providing financial support of this study under Research Grant No: SCU.SB98.477.

\section{References:}

[1] Huang, C. Xingwang, L. Lili, R. Jianping, Z. Yi, H. (2020) Clinical features of patients infected with 2019 novel coronavirus in Wuhan, China. The Lancet, 395(10223): 497-506. https://doi.org/10.1016/S0140-6736(20)30183-5

[2] Jiang, S. Du, L. Shi, Z. (2020) An emerging coronavirus causing pneumonia outbreak in Wuhan, China: calling for developing therapeutic and prophylactic strategies. Emerg. Microbes Infect. 9, 275277.

[3] Zhou, P. Yang, X.L. Wang, X.G. Hu, B. Zhang, L. Zhang, W. Si H.R. Zhu, Y. Li, B. Huang, C.L. Chen, H.D. Chen, J. Luo, Y. Guo, H. Jiang, R.D. Liu, M.Q. Chen, Y. Shen, X.R. Wang, X. Zheng, X.S. Zhao, K. Chen, Q.J. Deng, F. Liu, L.L. Yan, B. Zhan, F.X. Wang, Y.Y. Xiao, G.F. Shi, Z.L. (2020) A pneumonia outbreak associated with a new coronavirus of probable bat origin. Nature 579(7798):270273. https://doi.org/10.1038/s41586-020-2012-7.

[4] Lu, R. Zhao, X. Li, J. Niu, P. Yang, B. Wu, H. Wang, W. Song, H. Huang, B. Zhu, N. Bi, Y. Ma, X. Zhan, F. Wang, L. Hu, T. Zhou, H. Hu, Z. Zhou, W. Zhao, L. Chen, J. Meng, Y. Wang, J. Lin, Y. Yuan, J. Xie, Z. Ma, J. Liu, W.J. Wang, D. Xu, W. Holmes, E.C. Gao, G.F. Wu, G. Chen, W. Shi, W. Tan, W. (2020) Genomic characterisation and epidemiology of 2019 novel coronavirus: implications for virus origins and receptor binding. Lancet 395(10224):565-574. https://doi.org/10.1016/S0140$\underline{6736(20) 30251-8}$. 
[5] Wu, F. Zhao, S. Yu, B. Chen, Y.M. Wang, W. Song, Z.G. Hu, Y. Tao, Z.W. Tian, J.H. Pei, Y.Y. Yuan, M.L. Zhang, Y.L. Dai, F.H. Liu, Y. Wang, Q.M. Zheng, J.J. Xu, L. Holmes, E.C. Zhang, Y.Z. (2020) A new coronavirus associated with human respiratory disease in China. Nature 579(7798):265269. https://doi.org/10.1038/s41586-020-2008-3

[6] Chan, J.F. Yuan, S. Kok, K.H. To, K.K. Chu, H. Yang, J. Xing, F. Liu, J. Yip, C.C. Poon, R.W. Tsoi, H.W. Lo, S.K. Chan, K.H. Poon, V.K. Chan, W.M. Ip, J.D. Cai, J.P. Cheng, V.C. Chen, H. Hui, C.K. Yuen, K.Y. (2020) A familial cluster of pneumonia associated with the 2019 novel coronavirus indicating person-to-person transmission: a study of a family cluster. Lancet 395(10223):514-523. https://doi.org/10.1016/S0140-6736(20)30154-9 .

[7] Huang, C. Wang, Y. Li, X. Ren, L. Zhao, J. Hu, Y. Zhang, L. Fan, G. Xu, J. Gu, X. Cheng, Z. Yu, T. Xia, J. Wei, Y. Wu, W. Xie, X. Yin, W. Li, H. Liu, M. Xiao, Y. Gao, H. Guo, L. Xie, J. Wang, G. Jiang, R. Gao, Z. Jin, Q. Wang, J. Cao, B. Lancet 395(10223):497-506. https://doi.org/10.1016/S0140$\underline{6736(20) 30183-5}$

[8] Liu, S. et al.

Liu, S. Xiao, G. Chen, Y. He, Y. Niu, J. Escalante, C.R. Xiong, H. Farmar, J. Debnath, A.K. Tien, P. Jiang, S. (2004) Interaction between heptad repeat 1 and 2 regions in spike protein of SARS-associated coronavirus: implications for virus fusogenic mechanism and identification of fusion inhibitors. Lancet 363(9413):938-47.

[9] Lu, L. Liu, Q. Zhu, Y. Chan, K.H. Qin, L. Li, Y. Wang, Q. Chan, J.F. Du, L. Yu, F. Ma, C. Ye, S. Yuen, K.Y. Zhang, R. Jiang, S. (2014) Structure-based discovery of Middle East respiratory syndrome coronavirus fusion inhibitor. Nat. Commun. 5:3067. https://doi.org/10.1038/ncomms4067

[10] Li, F. Li, W. Farzan, M. Harrison, S.C. (2005) Structure of SARS coronavirus spike receptorbinding domain complexed with receptor. Science 309:1864-1868 
[11] Wrapp, D. Wang, N. Corbett, K.S. Goldsmith,J.A. Hsieh,C.L. Abiona, O. Graham,B.S. McLellan, J.S. (2020) Cryo-EM structure of the 2019-nCoV spike in the prefusion conformation. Science $367: 1260-1263$

[12] Coutard, B. Valle, C. de Lamballerie, X. Canard, B. Seidah, N.G. Decroly, E. (2020) The spike glycoprotein of the new coronavirus 2019-nCoV contains a furin-like cleavage site absent in $\mathrm{CoV}$ of the same clade. Antiviral Res. 176:104742. https://doi.org/10.1016/j.antiviral.2020.104742

[13] Kido, H. Okumura, Y. Takahashi, E. Pan, H.Y. Wang, S. Yao, D. Yao, M. Chida, J. Yano, M. (2012) Role of host cellular proteases in the pathogenesis of influenza and influenza-induced multiple organ failure. Biochim Biophys Acta. 1824(1):186-94. https://doi.org/10.1016/j.bbapap.2011.07.001

[14] Mbikay, M. Sirois, F. Yao, J. Seidah, N.G. Chrétien, M. (1997) "Comparative Analysis of Expression of the Proprotein Convertases Furin, PACE4, PC1 and PC2 in Human Lung Tumours.” Br J Cancer. 75(10):1509-14.

[15] Moulard, M. Decroly, E. (2000) "Maturation of HIV Envelope Glycoprotein Precursors by Cellular Endoproteases.” Biochim Biophys Acta, 1469(3):121-32.

[16] Xia, S. Zhu, Y. Liu, M. Lan, Q. Xu, W. Wu, Y. Ying, T. Liu, S. Shi, Z. Jiang, S. Lu, L. (2020) Fusion mechanism of 2019-nCoV and fusion inhibitors targeting HR1 domain in spike protein Cell Mol Immunol. https://doi.org/10.1038/s41423-020-0374-2. [Epub ahead of print]

[17] Yuan, Y. Cao, D. Zhang, Y. Ma, J. Qi, J. Wang, Q. Lu, G. Wu, Y. Yan, J. Shi, Y. Zhang, X. Gao, G.F. (2017) Cryo-EM structures of MERS-CoV and SARS-CoV spike glycoproteins reveal the dynamic receptor binding domains. Nat. Commun. 8, 15092 (2017). https://doi.org/10.1038/ncomms15092

[18] Xia, S. Yan, L. Xu, W. Agrawal, A.S. Algaissi, A. Tseng, C.K. Wang, Q. Du, L. Tan, W. Wilson, I.A. Jiang, S. Yang, B. Lu, L. (2019) A pan-coronavirus fusion inhibitor targeting the HR1 domain of human coronavirus spike. Sci. Adv. 5(4):eaav4580 (2019). https://doi.org/10.1126/sciadv.aav4580 
[19] Gui, M. Song, W. Zhou, H. Xu, J. Chen, S. Xiang, Y. Wang, X. (2017) Cryo-electron microscopy structures of the SARS-CoV spike glycoprotein reveal a prerequisite conformational state for receptor binding. Cell Res. 27(1):119-129. https://doi.org/10.1038/cr.2016.152

[20] Pallesen, J. Wang, N. Corbett, K.S. Wrapp, D. Kirchdoerfer, R.N. Turner, H.L. Cottrell, C.A. Becker, M.M. Wang, L. Shi, W. Kong, W.P. Andres, E.L. Kettenbach, A.N. Denison, M.R. Chappell, J.D. Graham, B.S. Ward, A.B. McLellan, J.S. (2017) Proc. Natl. Acad. Sci. U.S.A. 114(35), E7348E7357. https://doi.org/10.1073/pnas.1707304114

[21] Walls, A.C. Xiong, X. Park, Y.J. Tortorici, M.A. Snijder, J. Quispe, J. Cameroni, E. Gopal, R. Dai, M. Lanzavecchia, A. Zambon, M. Rey, F.A. Corti, D. Veesler, D. (2019) Unexpected Receptor Functional Mimicry Elucidates Activation of Coronavirus Fusion.

Cell 176(5), 1026-1039.e15. https://doi.org/10.1016/j.cell.2018.12.028

[22] Yuan, Y. Cao, D. Zhang, Y. Ma, J. Qi, J. Wang, Q. Lu, G. Wu, Y. Yan, J. Shi, Y. Zhang, X. Gao, G.F. (2017) Cryo-EM structures of MERS-CoV and SARS-CoV spike glycoproteins reveal the dynamic receptor binding domains. Nat. Commun. 8, 15092. https://doi.org/10.1038/ncomms15092

[23] Li, F. (2016) Structure, Function, and Evolution of Coronavirus Spike Proteins. Annu. Rev. Virol. $3: 237-261$.

[24] Bosch,B.J. van der Zee, R. de Haan, C. A. Rottier, P. J. (2003) The coronavirus spike protein is a class I virus fusion protein: structural and functional characterization of the fusion core complex. J. Virol. 77(16):8801-8811.

[25] Walls, A.C. Tortorici, M.A. Snijder, J. Xiong, X. Bosch, B.J. Rey, F.A. Veesler, D. (2017) Tectonic conformational changes of a coronavirus spike glycoprotein promote membrane fusion. Proc. Natl. Acad. Sci. U.S.A. 114(42):11157-11162. https://doi.org/10.1073/pnas.1708727114 
[26] Song, W. Gui, M. Wang, X. Xiang, Y. (2018) Cryo-EM structure of the SARS coronavirus spike glycoprotein in complex with its host cell receptor ACE2. PLoS Pathog 14(8): e1007236. https://doi.org/10.1371/journal.ppat.1007236

[27] Sheng, C. Ji, H. Miao, Z. Che, X. Yao, J. Wang, W. Dong, G. Guo, W. Lü, J. Zhang, W. (2009) Homology modeling and molecular dynamics simulation of $\mathrm{N}$-myristoyltransferase from protozoan parasites: active site characterization and insights into rational inhibitor design. J Comput Aided Mol Des. 23(6): 375 -89. https://doi.org/10.1007/s10822-009-9267-2

[28] Macindoe, G. Mavridis, L. Venkatraman, V. Devignes, M.D. Ritchie, D.W. (2010) HexServer: an FFT-based protein docking server powered by graphics processors. Nucleic Acids Res. 38-9

[29] Dayer, M.R. (2016) Comparison of Newly Assembled Full Length HIV-1 Integrase With Prototype Foamy Virus Integrase: Structure-Function Prospective. Jundishapur J Microbiol. 9(5):e29773. https://doi.org/10.5812/jjm.29773

[30] Johnson, V.A. Brun-Vezinet, F. Clotet, B. Gunthard, H.F. Kuritzkes, D.R. Pillay, D. (2008) Update of the drug resistance mutations in HIV-1: Spring 2008. Top HIV Med. 16(1):62 -8

[31] Dayer, M.R. Dayer, M.S. (2013) Whiskers-less HIV-protease: a possible way for HIV-1 deactivation. J Biomed Sci. 20:67

[32] Abdelouahab, C. Abderrahmane, B. (2008) Docking Efficiency Comparison of Surflex, a Commercial Package and Arguslab, a Licensable Freeware. J Comput Sci Syst Biol 1:081-086. https://doi:10.4172/jcsb.1000007

[33] Ritchie,D.W. Kozakov,D. Vajda, S. (2008)Accelerating Protein-Protein Docking Correlations Using A Six-Dimensional Analytic FFT Generating Function, Bioinformatics 24(17), 1865-1873 
[34] Hoffmann, M. Kleine-Weber, H. Krüger, N. Müller, M. Drosten, C. Phlmann, S. (2020) The novel coronavirus 2019 (COVID-19) uses the SARS-1 coronavirus receptor ACE2 and the cellular protease TMPRSS2 for entry into target cells. bioRxiv. https://doi.org/10.1101/2020.01.31.92904

[35] Glowacka, I. Bertram, S. Muller, M.A. Allen, P. Soilleux, E. Pfefferle, S. Steffen, I. Tsegaye, T.S. He, Y. Gnirss, K. Niemeyer, D. Schneider, H. Drosten, C. Phlmann, S. (2011) Evidence that TMPRSS2 activates the severe acute respiratory syndrome coronavirus Spike protein for membrane fusion and reduces viral control by the humoral immune response. J Virol 85(9):4122-4134. https://doi.org/10.1128/JVI.02232-10

[36] Iwata-Yoshikawa, N. Okamura, T. Shimizu, Y. Hasegawa, H. Takeda, M. Nagata, N. (2019) TMPRSS2 contributes to virus spread and immunopathology in the airways of murine models after coronavirus infection. J Virol. 93(6):e01815-18. https://doi.org/10.1128/jvi.01815 -18

[37] Chen, Y. Guo, Y. Pan, Y. Zhao, Z.J. (2020) Structure analysis of the receptor binding of 2019nCoV. Biochem Biophys Res Commun. 525:135e1402020. https://doi.org/10.1016/j.bbrc.2020.02.071

[38] Caly, L. Druce, J.D. Catton, M.G. Jans, D.A. Wagstaff, K.M. (2020) The FDA-approved drug ivermectin inhibits the replication of SARS-CoV-2 in vitro. Antiviral Res. 178:104787.

https://doi.org/10.1016/j.antiviral.2020.104787

[39] Mastrangelo, Eloise et al. (2012) "Ivermectin is a potent inhibitor of flavivirus replication specifically targeting NS3 helicase activity: new prospects for an old drug." The Journal of antimicrobial chemotherapy, 67(8):1884-94. https://doi:10.1093/jac/dks147

[40] Leone, S. Zuccoli, M.L. Fucile, C. Storace, S. Martelli, A. Mattioli, F. (2012) Heparin-induced acute adverse reaction--case report of a patient with acute trauma and a genetic predisposition to thrombotic events: a concurrence of events. J Clin Pharm Ther. 37(6):733-5. https://doi.org/10.1111/j.1365$\underline{2710.2012 .01360 . x}$ 
[41] van Gameren, M. Lemmert, M.E. Wilschut, J.M. Daemen, J. De Jaegere, P.P.T. Zijlstra, F. Van Mieghem, N.M.D.A. Diletti, R. (2018) An update on the use of anticoagulant therapy in ST-segment elevation myocardial infarction. Expert Opin Pharmacother. 19(13):1441-1450

[42] Mulloy, B. Hogwood, J. Gray, E. Lever, R. Page, C.P. (2016) Pharmacology of heparin and related drugs. A comprehensive review of the synthesis, structure, binding partners and pharmacology of heparin in a number of disease settings. Pharmacol Rev. 68:76-141.

[43] Riffo-Vasquez, Y. Somani, A. Man, F. Amison, R. Pitchford, S. Page, C.P. (2016) A nonanticoagulant fraction of heparin inhibits leukocyte diapedesis into the lung by an effect on platelets. Am J Respir Cell Mol Biol 2016, 55:554-563.

[44] Chandarajoti, K. Liu, J. Pawlinski, R. (2016) The design and synthesis of new synthetic lowmolecular-weight heparins. Journal of thrombosis and haemostasis. 14(6): 1135-45. https://doi.org/10.1111/jth.13312

[45] Ohe, M. Shida, H. Jodo, S. Kusunoki, Y. Seki, M. Furuya, K. Goudarzi, H. (2020) Macrolide treatment for COVID-19: Will this be the way forward? Biosci Trends. https://doi:10.5582/bst.2020.03058

[46] Ohe, m. Hashino, S. (2011) Successful treatment with erythromycin for idiopathic thrombocytopenic purpura. Korean J Hematol. 46(2): 139-142 https://doi.org/10.5045/kjh.2011.46.2.139

[47] Zimmermann, P. Ziesenitz, V.C. Curtis, N. Ritz, N. (2018). The Immunomodulatory Effects of Macrolides-A Systematic Review of the Underlying Mechanisms. Front Immunol, 9, 302. https://doi.org/10.3389/fimmu.2018.00302

[48] Altenburg, J. de Graaff, C.S. van der Werf, T.S. Boersma, W.G. (2011) Immunomodulatory effects of macrolide antibiotics - part 1: biological mechanisms. Respiration. 81(1):67-74. https://doi.org/10.1159/000320319 
[49] Xu, J. Shi, P.Y. Li, H. Zhou, J. (2020) Broad Spectrum Antiviral Agent Niclosamide and Its Therapeutic Potential. ACS Infect Dis. https://doi:10.1021/acsinfecdis.0c00052

[50] Cascella, M. Rajnik, M. Cuomo, A. Dulebohn, S.C. Di Napoli, R. (2020) Features, Evaluation and Treatment Coronavirus (COVID-19) [Updated 2020 Apr 6]. In: StatPearls [Internet]. Treasure Island (FL): StatPearls Publishing; 2020 Jan-. Available from:

https://www.ncbi.nlm.nih.gov/books/NBK554776/

[51] Basu-Ray, I. Soos, M.P. (2020) Cardiac Manifestations of Coronavirus (COVID-19). In: StatPearls [Internet]. Treasure Island (FL): StatPearls Publishing; Available from:

https://www.ncbi.nlm.nih.gov/books/NBK556152/

[52] Ghelichkhani, P. Esmaeili, M. (2020) Prone Position in Management of COVID-19 Patients; a Commentary. Arch Acad Emerg Med. 8(1):e48.

[53] Zhang, W. Zhao, Y. Zhang, F. Wang, Q. Li, T. Liu, Z. Wang, J. Qin, Y. Zhang, X. Yan, X. Zeng, X. Zhang, S. (2020). The use of anti-inflammatory drugs in the treatment of people with severe coronavirus disease 2019 (COVID-19): The Perspectives of clinical immunologists from China. Clin Immunol. (Orlando, Fla.), 214, 108393. Advance online publication. https://doi.org/10.1016/j.clim.2020.108393 [54] Zhang, L. Yan, X. Fan, Q. Liu, H. Liu, X. Liu, Z. Zhang, Z. (2020) D-dimer levels on admission to predict in-hospital mortality in patients with Covid-19. J Thromb Haemost.

https://doi.org/10.1111/jth.14859 [Epub ahead of print]

[55] Spiezia, L. Boscolo, A. Poletto, F. Cerruti, L. Tiberio, I. Campello, E. Navalesi, P. Simioni, P. (2020) COVID-19-Related Severe Hypercoagulability in Patients Admitted to Intensive Care Unit for Acute Respiratory Failure. Thromb Haemost. https://doi:10.1055/s-0040-1710018 [Epub ahead of print] 
[56] Tang, N. Bai, H. Chen, X. Gong, J. Li, D. Sun, Z. (2020) Anticoagulant treatment is associated with decreased mortality in severe coronavirus disease 2019 patients with coagulopathy. J Thromb Haemost. https://doi:10.1111/jth.14817 [Epub ahead of print] [57] Dayer MR. Old drugs for newly emerging viral disease, COVID-19: Bioinformatic Prospective. arXiv: 2003.04524, 2020-arxiv.org. https://arxiv.org/ftp/arxiv/ papers/2003/2003.04524.pdf (accessed April 1, 2020). 